(Mediatizaciones)

(Mediations)

(Midiatizações) 



\section{La perspectiva ecológica y la hipermediatización social}

\section{Eduardo Andrés Vizer ${ }^{1}$ Helenice Carvalho}

Recibido: 2015-04-08

Enviado a pares: 2015-04-08
Aprobado por pares: 2015-05-16

Aceptado: 2015-06-30

DOI: 10.5294/pacla.2015.18.4.6

Para citar este artículo / to reference this article / para citar este artigo

Vizer EA., Carvalho H. (Diciembre de 2015). La perspectiva ecológica y la hipermediatización social. Palabra Clave, 18(4), 1087-1110. DOI: 10.5294/pacla.2015.18.4.6

\section{Resumen}

La "ecología" de los medios no debe ser concebida como una especie de entorno que nos rodea y del cual somos el "centro", sino como un sistema de producción, circulación y consumo en el cual son los individuos, en tanto consumidores y (re)alimentadores del sistema, los que conforman su "entorno". Un abordaje ecológico de los medios tradicionales (radio, cine y televisión) introduce a los públicos consumidores como su entorno, y no al contrario (¿quién consume a quién?). Un entorno, un mercado que a través de prácticas de consumo realimenta al sistema de medios. Por otro lado, en los sistemas digitales, todos somos parte de él, no hay entorno externo, y cada acto de consumo es igualmente un acto de circulación y de producción. Para conocer la incidencia profunda de un dispositivo técnico (sea hard o soft), debemos indagar sobre las múltiples dimensiones interligadas e interactivas dentro del ambiente en el que opera: poder, resistencias, tiempo y espacio, socialidades, lenguajes, símbolos.

\section{Palabras clave}

Ecología, medios, mediatización, sistema, socioanálisis (Fuente: Tesauro de la Unesco).

\footnotetext{
Universidad de Buenos Aires, Argentina. eavizer@gmail.com

2 Universidad Federal del Rio Grande do Sul (Fabico/Ufgrs), Brasil. helecarvalho@gmail.com
} 


\section{The Social Ecological Perspective and Excessive Media}

\section{Abstract}

The "ecology" of means should not be conceived as a kind of environment that surrounds us and of which we are the "center", but as a system of production, circulation and consumption which are individuals, as consumers and (re) feeders of the system, which form the "environment". An ecological approach of traditional media (radio, film and television) introduces public consumers and the environment, and not the other (who uses whom?). An environment, a market through consumption practices fed to media system. On the other hand, in digital systems, we are all part of it, no external environment, and every act of consumption is also an act of circulation and production. For the profound impact of a technical device (whether hard or soft) we investigate multiple interconnected and interactive dimensions within the environment in which it operates: power, resistance, time and space, sociality, languages, symbols.

\section{Keywords}

Ecology, media, mediation, system, socio-analysis (Source: Unesco Thesaurus). 


\section{A perspectiva ecológica e a hipermidiatização social}

\section{Resumo}

A ecologia das mídias não deve ser concebida como uma espécie de ambiente que nos rodeia e do qual somos o centro, mas sim como um sistema de produção, circulação e consumo no qual são os indivíduos, enquanto consumidores e (re)alimentadores do sistema, os que conformam seu ambiente. Uma abordagem ecológica das mídias tradicionais (rádio, cinema e televisão) introduz os públicos consumidores como seu ambiente, e não ao contrário (quem consome quem?). Um ambiente, um mercado que, por meio de práticas de consumo, realimenta o sistema de mídias. Por outro lado, nos sistemas digitais, todos nós fazemos parte dele, não há um ambiente externo, e cada ato de consumo é, ao mesmo tempo, um ato de circulação e de produção. Para conhecer a incidência profunda de um dispositivo técnico (seja hard ou soft), devemos questionar sobre as múltiplas dimensões interligadas e interativas dentro do ambiente no qual opera: poder, resistências, tempo e espaço, socialidades, linguagens e símbolos.

\section{Palavras-chave}

Ecologia, mídia, midiatização, sistema, socioanálise (Fonte: Tesauro da Unesco). 
Seremos como dioses que perciben el comienzo y el fin al mismo tiempo, estaremos en todos lados simultáneamente, pero esa contemporaneidad plural nos servirá de poco. La utopía mediática nos decepcionará, como todas las ideologías. Querremos retornar a los viejos tiempos pero será imposible. Tal vez podremos retornar, pero no nadando como los peces en un río sino sentados en nuestras mesas. Con la aceleración de imágenes inmateriales estaremos cerca del tiempo final. Podremos estar en todos lados, pero no nos servirá porque seremos inmateriales como alguien que observa, no como al-

guien que vive.

Versión libre sobre un texto original de Vilém Flusser, filósofo checo de los medios (1990)

Cuando hace ya muchos años debimos hacer el programa de una materia en los cursos de comunicación, escribimos (tal vez algo ingenuamente) que los periodistas y los comunicadores sociales eran "responsables por la ecología mental” de sus lectores y telespectadores. Estábamos claramente exagerando el poder y la autonomía de los comunicadores respecto a los medios en que trabajan ( $y$ tal vez exagerando también el poder específico de los medios dentro el conjunto de los poderes que operan en la sociedad) y sobre todo en relación con los periodistas, siempre sujetos a los condicionamientos de los jefes de redacción, los patrones, los anunciantes y los dueños y accionistas de las corporaciones mediáticas.

A partir de McLuhan (1964), Neil Postman (1992) y otros pensadores e investigadores de los medios, la metáfora ecológica ha ido ganando terreno. ¿Qué mejor manera de concebir la omnipresencia siempre inmanente e invasiva de imágenes, textos, datos, música, sonidos, propaganda, información y estímulos de toda clase sobre los diferentes sentidos y órganos sensoriales de miles de millones de seres humanos? ¿O el martilleo interminable de estímulos que surgen de los miles de dispositivos técnicos de información y comunicación con los que nos vemos obligados a convivir diariamente? Ya ni siquiera estamos obligados a ir hacia ellos, prenderlos, apagarlos y manipularlos con las manos. Ellos vienen hacia nosotros desde innumerables pantallas, están en nuestros bolsillos - como los celulares y smartphones-, están multiplicándose como hongos a través de cámaras escondidas en las calles, en árboles y en edificios de cualquier ciudad "moderna y res- 
petable" del mundo. Están en nuestras viviendas, y hasta en el ascensor del edificio en que vivimos (la seguridad ante todo). Están espiando y registrando cada mensaje que enviamos o recibimos, están siendo inseridos industrial y gradualmente en nuestros objetos de uso cotidiano por medio del proceso denominado difusamente "Internet de las cosas", y hasta están comenzando a ser usados como punta de lanza nanotecnológica a fin de atravesar nuestra piel, nuestros órganos internos y el cerebro con fines de control médico, para prevenir a tiempo "desequilibrios" en el funcionamiento del organismo o para detener un ataque de microorganismos indeseados (ya sea desde nuestros propios cuerpos o provenientes del medio externo). El funcionamiento de nuestro sistema biológico, así como el del entorno físico de las ciudades, el agua y la energía disponibles, están todos siendo permanentemente monitoreados por dispositivos y sistemas específicos y expertos (¿inteligentes?). ${ }^{3}$

Realmente, parece que la metáfora ecológica se acerca mucho a la realidad. Más aún, la bioingeniería y la medicina desarrollan dispositivos que parecen amalgamar nuestros propios cuerpos con cuerpos extraños - tecnológicos, biológicos o biotecnológicos-. Somos día a día más dependientes de dispositivos técnicos, maquinarias, operaciones y diferentes objetos y elementos del medio físico, hasta el punto que se hace difícil establecer claras separaciones entre el mundo biológico y el tecnológico, entre el "adentro" y el "afuera" y aun entre el ego y lo Otro (con la crisis de la modernidad, la tradicional separación idealista entre la subjetividad personal y el mundo físico — ambos mediados por la tecnología — disminuye paulatinamente, y la separación entre el "yo" y el Otro aumenta, a pesar de las redes sociales y los amigos digitales). En el mundo social, político y económico, si todo tiende a estar permanentemente conectado entre sívirtualmente, y regulado por mecanismos sujetos a operaciones algorítmicas preestablecidas en programas informatizados, las consecuencias a mediano y largo plazo serán no solo inevitables sino profundas - y seguramente irreversibles - para cualquier institución y cualquier sociedad (mas allá de su sistema político, de su cultura o idiosincrasias particulares).

3 En La caja de Pandora: tendencias y paradojas de las TIC (2012a, p. 174), presentamos 20 diferentes tendencias que se observan en los procesos de hipermediatización de la sociedad a partir de las TIC. 
Nos basta observar las profundas implicancias de los procesos de globalización de los mercados en todo orden, que generan valores, normas y prácticas similares a fin de asegurar el "acople" de un país, un sistema productivo, un gobierno y las instituciones al funcionamiento del sistema global. La palabra de orden es que "todo debe entrar", y nada puede permanecer "afuera" (del mercado, del sistema, del mundo de las ideas), a riesgo de condenarse al ostracismo y el atraso. No siempre se entiende bien que el principal "efecto" de la implantación de las tecnologías de información y comunicación a largo plazo no consiste tanto en optimizar ambos procesos, sino en integrar a un mismo sistema a sujetos, instituciones, prácticas y procesos socioeconómicos que aún funcionan en forma separada o autónoma (la integración a mercados mundiales y los procesos de globalización son un perfecto ejemplo de lo que decimos).

Otro tanto se observa en los avances imparables de la convergencia entre los medios de comunicación y las tecnologías de la información y, sobre todo, en los aplicativos y la explosión de las comunidades en red y las redes sociales: quien se anima a permanecer "afuera" se autocondena a diferentes formas de ostracismo. No hace falta separar el cuerpo de un ciudadano de los otros cuerpos, de su medio físico, de sus derechos políticos. Simplemente se torna opaco, invisible e irrelevante a los ojos de los demás. Peor aún, el ciudadano ha perdido su identidad social. Aunque se trate de un profesor, un intelectual, un escritor, un artista o un profesional brillante, la no presencia en el mundo virtual lo condena a ser una figura de museo, un sobreviviente de otros tiempos previrtuales. Conocemos a un brillante académico de la Universidad de Toronto (filósofo y sociólogo) que se niega a renegar de su máquina de escribir aunque le cueste la pérdida gradual de su reconocimiento por parte de los jóvenes estudiantes de sociología. Imposible negar cierta decepción y una sensación de passè al momento de escuchar esta confesión de la propia boca de este profesor. Inconscientemente, nuestra percepción y valoración de su obra y su persona parecían mudar de la presencia del presente hacia la de un pasado, a la vez tan cercano en el tiempo y tan lejano en su práctica.

Como contrapartida, cualquiera capaz de operar dispositivos digitales, aun si se tratase de un analfabeto funcional que jamás en su vida haya 
leído un libro completo, puede grabar a su gato caminando sobre el teclado de un piano, o los primeros pasos graciosos de su hijo, subirlo a la web y hacerse famoso por 24 horas. En el mundo intelectual algunos han creado la noción de pensamiento único, presentando nuestra sociedad actual como un mundo "plano", sin relieves y sin capacidad de reflexividad crítica. En los años noventa, antes de las redes sociales, Neil Postman bautizó las nuevas tendencias sociales y culturales con el sugestivo título de tecnopolio, y Vizer, a comienzos de los ochenta, como cultura tecnológica. Más allá de los títulos, la referencia implícita alude a la importancia creciente y acelerada que las tecnologías, la técnica y en especial los dispositivos TIC vienen cobrando en un brave new world que no tiene nada de brave y tal vez ni siquiera de new en sus contenidos, aunque tal vez sí en sus formas de expresión, en sus lenguajes especializados, en sus programas de acción informatizados y sobre todo en sus formas y dispositivos de control social.

En El ojo de Dios. Conectados y vigilados (2012c), nos referimos a ciertas consecuencias aceleradas y peligrosas que la universalización de los dispositivos de espionaje (recolección y conservación de información personal) están representando para la humanidad sujeta a un paradigma tecnológico de control social, sostenido por la voluntad geopolítica de poder, dominio político militar de sociedades más débiles y apropiación de sus recursos naturales. La gran diferencia entre los imperios y los poderes del pasado y los actuales estriba en el uso masivo, omnipresente y sistémico de las tecnologías digitales, y la técnica como paradigma asimilado al uso del poder. Un poder que sostiene un discurso despersonalizado (¿deshumanizado?) y sistémico: en la cultura tecnológica de la democracia no hacen falta dictadores ni personalismos, la racionalidad de la supervivencia (ya de sea de instituciones, de sectores sociales, o de estados nacionales) estriba en tomar las únicas decisiones correctas que lleven a la integración a los mercados, al equilibrio del sistema, al sostenimiento de la moneda (valen los ejemplos de los nuevos gobiernos tecnócratas de la Europa del euro, o los controles en el área del dólar). Cuando el discurso del pensamiento único se impone como el único paradigma de la racionalidad y la supervivencia de comunidades y países enteros, se eliminan los discursos, las instituciones y los grupos sociales que no adhieren al paradigma salvador de la tecnocracia, y se instalan 
a través de los medios de comunicación los mecanismos y los argumentos de denigración del pluralismo y del disenso. Se instala el paradigma de las antinomias y la racionalidad tecnocrática como única racionalidad posible (¡tecnocracia o caos!). Su "lógica” no deja lugar a dudas ni alternativas "o $\mathrm{X}$ o Y” y desaparece el resto del abecedario. Los medios de comunicación no se cansan de repetir el discurso de la inevitabilidad, y así toda una ecología simbólica y cultural de pueblos enteros entra en crisis. El miedo al caos, la disgregación y la violencia son mecanismos psicológicos cuidadosamente cultivados por ciertos gobernantes obsesionados por el poder y el control, por la mayoría de los grandes medios y en última instancia por el "sistema”. Volvamos a la metáfora ecológica: cuando el entorno presente y el futuro inmediato se vuelven inciertos y peligrosos, todos pretenden buscar refugio en el sistema. Y se aplica el dicho tradicional de "más vale malo conocido que bueno por conocer". El escritor George Orwell señaló bien en su obra 1984 la necesidad permanente de un enemigo externo y la guerra incesante para mantener a la sociedad "protegida" dentro de la organización y las fronteras del sistema. En nuestros días, la guerra al terror y la sospecha hacia el islamismo fundamentalista cubren esta función a la perfección.

\section{Mediatización, ecología y mercado}

Podemos afirmar sin lugar a dudas que los dispositivos mediáticos, sus productos y los procesos infocomunicacionales tienen su principal objetivo y punto focal de convergencia sobre cada actor social, ya sea individuo, grupo, públicos políticos o mercados privados. Por lo tanto, no parece exagerado afirmar - desde la perspectiva de cada individuo, cada actor social y paulatinamente para toda clase de instituciones- que las tecnologías de información y comunicación se presentan intuitivamente como un verdadero entorno mediatizante. Una pregunta interesante - aunque aparentemente obvia- es: ¿cuál es el "sujeto" central de este sistema mediático, de este proceso ecológico conformado por señales, imágenes, datos y relatos construidos por la cultura tecnológica de occidente y universalizada en el breve tiempo del siglo XX? El individuo, en tanto "sujeto mediatizado" del siglo XX, se constituyó en realidad como un sujeto pasivo, y su propia existencia responde a un "lugar" construido por los mercados de 
consumo cultural. Su propia identidad contemporánea se constituye en el momento en que entra a este mercado de consumo, ni antes ni después. Se constituye en sujeto en el propio acto de consumo. Dos consecuencias directas podemos sacar de esto: 1) por un lado, histórica y sociológicamente hablando, el origen del proceso fundante no se halla en el individuo, en sus capacidades y necesidades innatas - a pesar de las apariencias que muestran el sentido común y los propios medios, interesados en cultivar un discurso populista e individualista-, sino en la sociedad industrial capitalista, que ha creado no solo la tecnología sino un mercado económico y, con él, los hábitos y las prácticas de consumo para sus productos. 2) Por otro lado, nos interesa resaltar que — si se acepta la hipótesis anterior — la concepción ecológica de los medios precisa de una redefinición: ya no es una "ecología de medios" o mediática que circunda o envuelve a los individuos (en tanto públicos, lectores, oyentes o consumidores), sino un sistema de producción que, al mismo tiempo que crea (los productos mediáticos), crea también a sus consumidores, a los sujetos individuales de consumo. En una palabra: crea sus públicos. La "ecología" de los medios no precisa entonces concebirse como una especie de "entorno" para todos y cada uno de nosotros, sino un sistema de producción para el cual son los individuos en tanto consumidores los que conforman el "entorno" del sistema. Un abordaje ecológico de los medios tradicionales (radio, cine y televisión) introduce a los públicos consumidores como su entorno, y no viceversa. Un entorno, un mercado que a través del consumo realimenta al sistema de medios.

Las líneas anteriores se refieren específicamente al auge y el éxito de los medios masivos en el siglo pasado, y pueden parecer obvias para muchos especialistas, pero merecen destacarse para romper una imagen pública algo ingenua que se ha extendido sobre la noción de ecología de los medios. Pero el cuadro del siglo XXI es totalmente diferente; los nuevos medios digitales y las TIC han comenzado a redefinir desde sus bases a todo el campo de los medios, los procesos y los dispositivos de información y de comunicación. Hace ya varios años, decíamos que:

Las TIC conforman una infraestructura mediatizadora por la que circulan imágenes y textos que realimentan una economía simbólica, un mercado de valores inmateriales que crece en forma exponencial. $Y$ 
esto nos pone ante una revolución cultural: los propios bienes simbólicos que circulan por las redes globales tienden a una creciente autonomía -0 desfazaje- de sus procesos de producción originales, generando valores (o dis-valores) en la forma de externalidades (positivas o negativas). Los procesos de trabajo y de producción material pasan a ser secundarios y dependientes de los procesos y las redes de circulación de información, de textos y productos. Gracias (0 a pesar) de las TIC, la economía real está comenzando a ser dependiente de una economía simbólica -economía "inmaterial"-, donde la creación de valor se ha disociado del trabajo y la producción material.

En aquellos años, faltaba aún bastante para que los subprime y los bonos basura estallaran en la crisis del 2008 y para que el término "derivativos financieros" se transformara en mala palabra, casi sinónimo de pura especulación sin contrapartida económica real. Gracias a las TIC y al acceso a información privilegiada, la especulación se hizo global e instantánea a través del análisis de probabilidades matemáticas de ganancia con inversiones sobre bonos, acciones, materias primas, propiedades inmuebles y monedas de cualquier país. A partir del nacimiento del capitalismo, la especulación tomó un papel importante para los procesos de circulación e inversión de capitales, pero las TIC expandieron y aceleraron el proceso de manera exponencial. Cualquier objeto o bien (natural, social o cultural) pasa a ser traducido a un valor económico, adaptado y apropiado a mecanismos de mercado (como reservas de recursos naturales, como capital social de una comunidad o como derechos de autor).

Las TIC proporcionan una capacidad de crecimiento exponencial para la recolección de información y el registro y la circulación de datos a escala global. El dinero (en este caso el capital de inversión) puede así “acoplarse" a todos estos procesos mediante un cálculo de probabilidades de ganancia (o de especulación). Los dispositivos de las TIC conforman así una infraestructura física y material (hardware) que mientras "cubre y penetra" la sociedad real (individuos e instituciones), traduce todo en bits de información, procesados y transmitidos en tiempo real (o sea tiempo presente). En teoría, cualquier conjunto de datos, de información, de textos o de imágenes puede ser objeto de especulación financiera, puede transformarse en un valor en el mercado. De este modo, tal vez las TIC - y la consiguien- 
te estructuración de una economía de la información que emerge gracias a ellas - seguramente no han "creado" la nueva economía cognitiva, pero la han expandido y acelerado hasta el punto de transformarla en una nueva ecología tecnoinformacional. En las próximas páginas tomaremos a Facebook como un caso de éxito ejemplar que reúne de manera paradigmática los procesos a los que estamos refiriéndonos aquí.

El sistema de producción posindustrial requiere de estas capacidades de comunicación y de búsqueda, registro y procesamiento de información cada vez más sofisticadas para competir en un mercado donde los servicios, la atención al cliente, la creatividad e imaginación, la respuesta inmediata, la capacidad de procesamiento de la información y la interpretación de situaciones y eventos conforman el principal valor agregado de una marca. Y esto es común tanto a la producción industrial y el consumo masivo, como a los nuevos nichos de mercado, donde la incertidumbre y las oportunidades van de la mano con la capacidad de innovación, flexibilidad y reflexividad.

La circulación y el flujo ininterrumpido de los procesos de (re)producción mediática genera una iconosfera que no solo circunda a los seres humanos sino que los "penetra" a través de los sentidos principales. La ecología mediática del hombre y la mujer contemporáneos seguramente condiciona no tanto los "contenidos" de lo que percibimos sino cómo y desde qué categorías mentales y modalidades de recepción — conscientes o inconscientespercibimos y construimos interpretaciones y damos sentido y coherencia a la invasión constante de estímulos visuales y auditivos. Es imposible la vida humana sin la existencia de filtros y parámetros que seleccionen y organicen el caos de estímulos. Tanto la cultura como el proceso de socialización y la historia personal de cada uno van ayudando a construir ciertos marcos de referencia que ayudan a organizar los estímulos en "textos" con sentido, por mas esquemáticos y elementales que puedan ser. En otras palabras, no se puede hablar de determinismo tecnológico, sino de "interacción" hombre-máquina, de interdependencia o aún codependencia mutua. Hasta tal punto esto es así que hoy podemos llegar a sospechar que la optimista afirmación de McLuhan de que "los medios son extensiones del hombre" en muchos casos puede invertirse. Así como Chaplin mostraba en el cine al 
operario como extensión de la máquina en los años cuarenta, hoy no sabemos hasta qué punto nuestros niños y jóvenes se hallan condicionados por los videojuegos, la computadora y la infinidad de nuevos dispositivos que constituyen sus contextos de interacción y mediación con el mundo real.

La tradición americana de los estudios de comunicación puso el centro de interés de las investigaciones en los "efectos" de los medios, ya sean directos o indirectos, a corto o largo plazo. Pero no avanzó mucho sobre las implicancias profundas y culturales de los procesos de convergencia y reconversión de los medios y los procesos de "apropiación activa” y crítica por parte de los receptores. La escuela norteamericana tendía a partir de un conductismo no declarado y de la perspectiva de las behavioral sciences, poniendo el acento en las conductas y respuestas del receptor. La profundidad del cambio cultural y ecológico promovido por las tecnologías mediáticas pasaba a un segundo plano que escapaba al paradigma experimental vigente para las ciencias de la conducta. Por otro lado, los media studies permanecían atrapados en el marco de los estudios sociológicos, dejando también escapar en ambos casos la especificidad de los impactos globales y sistémicos de las tecnologías, las organizaciones y las operaciones de sentido que deben constituir los núcleos de la investigación sobre los procesos de mediatización social.

\section{Ecología e hipermediatización}

En el periódico Clarín de Buenos Aires, el día 11 de febrero del 2012, se reprodujo una nota titulada "Una posición sobre privacidad", traducida de The New York Times:

Max Schrems, un estudiante de derecho de 24 años originario de Salzburgo, Austria, quiso averiguar qué sabía Facebook. Lo que recibió fue prácticamente una novela de 1.222 páginas. Contenía notificaciones en el muro que había borrado, mensajes viejos que revelaban el estado mental perturbado de un amigo, y hasta información sobre su paradero físico que ni siquiera había ingresado. Schrems sintió una vaga inquietud respecto de lo que Facebook podía llegar a hacer con toda esa información. Se preguntó en primer lugar: ¿por qué estaba ahí si él lo había borrado? "Es como una cámara colgada sobre la cama cuando estás teniendo sexo. No está bien", dijo. "Nosotros en Europa estamos muy asustados con lo que podría llegar a 
pasar algún día". El sentimiento de Schrems resume el malestar que recorre toda Europa en relación a como tratan la información personal las empresas de Internet. Luego prosigue "Los datos personales son el aceite que lubrica Internet. Cada uno de nosotros está sentado sobre sus enormes reservas personales. Los datos que compartimos todos los días... ayudan a que las empresas orienten la publicidad sobre la base no solo de la demografía, sino también de las opiniones y los deseos personales que subimos online. Estos ingresos publicitarios reportan a su vez cientos de millones de dólares a empresas como Facebook".

Es en este sentido que en El ojo de Dios: conectados y vigilados habíamos insistido precisamente en que se deben analizar hasta sus últimas consecuencias los riesgos de la omnipresencia de las tecnologías que nos circundan: desde los satélites, pasando por la vigilancia implícita en las redes sociales, la geolocalización a través de nuestros celulares o la infiltración (camfecting) de nuestras webcams personales, que pueden ver, oír y registrar todo, además de casi toda nuestra intimidad.

A estas alturas, seguramente algún lector se preguntará qué tiene que ver esta capacidad peligrosamente "controladora" de las TIC con un abordaje ecológico (tanto de los tradicionales medios masivos como de los ya no tan nuevos - medios de información y comunicación digitales). Sin embargo, un análisis bastante obvio pero cuidadoso nos muestra la evidencia de la presencia de tecnologías de información, registro y difusión crecientemente articuladas y convergentes entre sí. Esta convergencia es la responsable directa de generar nuestro panopticum digital del siglo XXI, ya que sin ella la posibilidad de articular múltiples dispositivos diferentes de observación, registro, memoria, difusión e intercambio de datos e informaciones no hubiera sido posible, y por ende la construcción de sistemas de control operativo y las redes complejas como las que existen hoy en el mundo virtual (debemos recordar que para Pierre Lévy [2007] el ciberespacio emerge de la interconexión mundial —y material— de los ordenadores).

El paradigma ecológico surge sobre todo por una inquietud epistemológica de investigadores y científicos disconformes con la tradición científica tradicional, que buscó reducir los análisis de los hechos (naturales o sociales) a relaciones simples y demostrables entre unos pocos elementos 
seleccionados dentro de un proceso o un conjunto objetivamente complejo de elementos o de actores, tal como podemos observar intuitivamente en los hechos y las realidades que percibimos y vivimos cotidianamente. Cualquier hecho social, natural y aun técnico implica procesos intrínsecamente interrelacionados desde su propio origen, y las tecnologías seguramente lo son más aún, dada la complejidad y cantidad de actores involucrados, de intereses económicos y financieros de todo tipo, de necesidades, fantasías, ambiciones y expectativas.

Retomando "el caso Facebook", vemos la multiplicidad de hechos y procesos que logra desencadenar: desde la perspectiva económica y la influencia en diferentes mercados, hasta los impactos y las transformaciones sociales y culturales que está imponiendo en las relaciones sociales, en la política y en las nuevas modalidades de representación de la realidad natural, social, cultural e individual. La contundencia y velocidad con que se impusieron tecnologías como la telefonía celular o las redes sociales (Facebook, Twitter, etc.) solo se explica por la convergencia feliz de una multiplicidad de factores que sus creadores generalmente no imaginaron en su momento. Una de las razones principales del éxito universal de la telefonía celular en todas las culturas y todos los niveles socioeconómicos se debe a que coincide con las tendencias sociales a la individuación y la necesidad de autonomía y movilidad personal. De haber sido inventado en otro momento histórico, tal vez hubiera corrido la suerte del científico griego que hace dos mil años descubrió que el vapor de agua podía generar movimiento, pero solamente la Revolución Industrial permitió su aplicación a un cilindro que mueve las piezas de un motor diseñado en la forma que permita una combustión interna. Y Facebook no hubiera tenido el éxito arrasador que logró si la cultura mediática del siglo XX no hubiera instalado y socializado en pocas generaciones los nuevos imaginarios populares sobre la forma de relatar historias, la existencia del cine como vida proyectada en imágenes, fotografías organizadas en álbumes familiares o individuales, y ahora la subjetividad y la autorreferencia canalizadas y compartidas de manera desenfrenada y sin tabúes con avatares o con amigos reales o virtuales desconocidos (¿cómo hubiera reaccionado Freud a todo esto en el mundo burgués del siglo XIX, todavía signado por las inhibiciones y la represión sexual, y donde la vida privada aún se hallaba totalmente divorciada de la pública?). 
Las investigaciones empíricas sobre los resultados de la introducción y el uso de tecnologías representan un volumen creciente del tiempo y los recursos volcados en los ámbitos académicos y privados. Estudiar el impacto tecnológico está rodeado de cierto halo contemporáneo asociado a lo práctico, lo medible, lo importante y científico (además de que favorece la búsqueda de fondos para la investigación aplicada). Mucha investigación empírica ha permitido acrecentar bancos de datos y favorecer aplicaciones prácticas en ámbitos de trabajo y para la educación. Sin embargo, no es fácil hallar ejemplos de investigaciones que vayan más allá de la búsqueda de relaciones o asociaciones estadísticas entre la introducción de un dispositivo nuevo y el aumento de la productividad en el ámbito laboral, el mejoramiento de las relaciones humanas en las instituciones, la capacidad de aprendizaje de alumnos en la escuela o la universidad, o el grado de satisfacción en la participación en redes sociales. Bajo ningún motivo se debe entender esto como una crítica a estas investigaciones, sino a cierta limitación teórica y cierto reduccionismo que no toma en consideración las múltiples modificaciones — sistémicas - que se producen con la implantación de tecnologías nuevas o diferentes: en ámbitos de trabajo, de ocio, de estudio, en diferentes sectores etarios, en grupos y culturas diversas, en los procesos subjetivos y emocionales, en la creación de vínculos y relaciones sociales y familiares, etc.

Según el investigador Barry Wellman (2004), existen tres etapas que se pueden diferenciar en las investigaciones académicas de Internet. Una primera, caracterizada por ensayos de corte optimista sobre la capacidad y poder de transformación de Internet; una segunda, de naturaleza empírica centrada en documentar sus usos, y, por último, una fase que pasa de estudios descriptivos a una elaboración más analítica que investiga la vida cotidiana en relación con las redes. Esto último - y la construcción de un nuevo campo de los Internet studies - implica el pasaje a investigaciones interdisciplinarias, con fuerte impronta sociocultural y la articulación de las ciencias sociales con las ciencias de la información y la comunicación, y con temáticas amplias como la sociedad en red, la sociedad de la información y del conocimiento, etc. 
Respecto a los problemas de las investigaciones sobre las influencias de las TIC, podemos afirmar que lamentablemente muchas investigaciones sobre las relaciones entre las TIC y los ambientes en que son instaladas (fábricas, escuelas, sectores gubernamentales, medios de comunicación, etc.) tienden a ser abordadas en forma demasiado lineal: impacto, eficiencia, ahorro de tiempo y espacio, etc. Pensamos que este tipo de abordajes "micro" son sumamente acotados y pierden de vista el panorama mayor: la transformación del contexto en que se insertan las TIC como organizaciones y sistemas complejos y multidimensionales. Por esta razón, preferimos un marco de análisis no reduccionista que aborde las múltiples dimensiones en las que se dan las prácticas de individuos y organizaciones. En otras palabras, preferimos realizar un abordaje "ecológico" de las implicancias que conlleva la adopción de las TIC en toda clase de contextos sociales. En principio, parece haber dos "puntos de partida": 1) el primero consiste en analizar los cambios y modificaciones que nos interesan tanto en el antes como en el después de la introducción de una tecnología en un determinado ambiente, con lo que estaríamos poniendo al objeto técnico como la variable central de cambio y disminuyendo el papel que juegan los actores sociales y su subjetividad; 2) el segundo punto de partida (que no se opone al anterior) pone el centro de la investigación en el contexto social y cultural, en los seres humanos y en su forma de apropiarse e interactuar con los objetos técnicos. En estos casos la noción de mediación — así como la de traducción- es central: los dispositivos y la técnica se conciben como mediadores socioculturales en el seno de contextos sociales en los cuales emergen nuevas relaciones hombre(s)-máquina, usuario(s)-tecnologías.

Podemos comenzar por considerar la segunda perspectiva como más amplia y ecológica, ya que elige un conjunto hombre-máquina como una totalidad, sin poner a la tecnología como el determinante central. Sabemos que el éxito de un dispositivo depende en última instancia del juego mutuo entre el actor social (individuo, grupo, empresa o institución) y las posibilidades que ofrece el objeto técnico para lograr ciertos fines buscados por el actor. Pero también sabemos que la máquina es capaz de condicionar las formas de acción y de percepción, los lenguajes operativos y el contexto de uso. El "ambiente ecológico" es cocreado a través de las relaciones hombre-máquina, y es esta relación compleja e interdependiente entre ambos la 
que llevó en los años noventa a autores como Bruno Latour (2005) a una sociología de las asociaciones y a la teoría del actor-red propuesta por él, a fin de construir una perspectiva ecológica que piensa los procesos sociales como una consecuencia de las interrelaciones entre agentes humanos y no humanos, considerando al objeto técnico también como un "actor" o "actante". Con esto se busca superar ciertas antinomias como sociedad-naturaleza y sujeto-objeto, "instituyendo un pensamiento que reconoce apenas híbridos que se constituyen en toda acción formada por mediadores y traductores, los actantes" (Lemos, 2011). Evidentemente, esta teoría intenta poner en pie de igualdad las influencias mutuas entre ambos términos: hombre y máquina (e intentando al mismo tiempo superar la antinomia sujeto-objeto). Sin embargo, esta equivalencia puede seguramente abordar una descripción de procesos con bastante objetividad, pero lo que no puede es determinar los objetivos y los valores que guían la apropiación humana de las máquinas. Porque, en última instancia, es el criterio de apropiación humana el que debería orientar los usos y fines que se den a las máquinas.

Una forma no reduccionista de investigar las interrelaciones entre tecnología y contexto social o entre hombre y máquina puede consistir en un abordaje descriptivo y heurístico como el que proponemos con el socioanálisis (Vizer, 2003). Con él pretendemos abarcar un cuadro ecológico amplio que cubre diferentes dimensiones de análisis, que desde una perspectiva sistémica permiten abordar cada tópico, cada hecho o proceso como un (sub)sistema interligado a un contexto mayor. De este modo aspectos técnicos, la toma de decisiones, el control del espacio, las relaciones entre agentes de una organización y sus dimensiones culturales pueden ser analizados respetando la especificidad de cada cuestión analizada y su grado de "autonomía" en relación con el ambiente mayor, donde se produce una reorganización funcional del sistema. Es decir: la implantación de una nueva tecnología como generadora - yluego reproductorade nuevas relaciones técnicas, nuevas modalidades de generación de lazos sociales, actitudes, valores y modos compartidos de recrear las condiciones existentes en un ambiente productivo o bien un modo de vida, favoreciendo la modificación o el fortalecimiento de dispositivos ya establecidos en un colectivo social. 
Esto permite explorar sobre cuáles ámbitos y dimensiones socioculturales incide de forma sistémica la introducción "ecológica" de una tecnología: desde un nivel estrictamente operativo y funcional, pasando por aspectos que abarcan cuestiones de concentración de la autoridad y el poder de decisión, las modificaciones —o desaparición — de jerarquías (sobre todo en las organizaciones), pasando luego por los cambios en el uso y la distribución de los espacios físicos con sus objetos específicos (lugares de trabajo o de ocio, muebles, máquinas, etc.). Se puede observar el funcionamiento de mecanismos de regulación de los diversos tiempos requeridos para la realización de determinadas tareas, ya sea como trabajo físico o intelectual (en la literatura marxiana denominada como trabajo inmaterial, lo que tiende a llevar a la idea errónea de que el trabajo intelectual no implicaría materia física, dificultando asílos criterios de cálculo sobre el valor y el tiempo en el trabajo intelectual). La introducción de TIC también incide en las relaciones y los vínculos interindividuales e interreferenciales y subjetivos entre miembros y agentes de una organización, y en sus modos de comunicarse, así como sobre los procesos simbólicos que ordenan las representaciones colectivas y la adjudicación de sentido. Debemos tomar en cuenta en nuestros análisis también los procesos de "institución simbólica" de las instituciones y los diversos órdenes sociales (o lo que comúnmente se denomina imprecisamente como "cultura", que puede a su vez considerarse como la ecología simbólica que se crea a la par de las prácticas en una organización o una comunidad, ya sea esta real o virtual).

\section{Conclusión: el "caso" Facebook. What's new?}

Para ir concluyendo este trabajo, retomemos el caso Facebook. Para conocer la real incidencia "ecológica" de Facebook y las prácticas sociales asociadas a él debemos preguntarnos sobre sus implicancias en relación con las siguientes dimensiones:

a) Facebook en tanto dispositivo "técnico y funcional". Su operatividad y accesibilidad en relación con diferentes tipos de usuarios, modalidades de acceso, aprendizajes, interactividad, formas de acceder a objetivos (de trabajo, estudio, investigación, expresión artística, etc.) 
b) Facebook en relación con aspectos relacionados con formas de poder y control, condiciones de ingreso, grados de libertad que permite ejercer tanto "internamente" como en relación con el orden social "externo": político, social, jurídico y cultural. Usuarios y usos asociados a formas de poder y control. Discursos, lenguajes y símbolos; sus modalidades "represivas”.

c) Facebook como dispositivo de "resistencia" a los aspectos y dimensiones anteriores. Formas, modalidades de expresión y canales de ejercicio de libertad, oposición y creatividad. Límites sociales y culturales, tipos y grados de vinculación que permite con actores externos, etc. "Discursos, lenguajes y símbolos" que hipotéticamente representan antinomia, oposición y alternativas en relación con los discursos y lenguajes empleados o sugeridos en la dimensión anterior (por ejemplo, discursos "críticos", propositivos o de "resistencia", links y declaraciones como los que desarrollan movimientos alternativos).

d) Facebook y la "dimensión temporal y espacial". Esto implica tanto los aspectos de espacialidad física en relación con el dispositivo material como la espacialidad y la construcción de tiempos virtuales: preguntarnos cómo Facebook diseña, articula y relaciona los elementos de sus páginas para generar en el usuario encadenamientos espaciales y temporales de sentido. Implica también la existencia de hiperlinks como construcción de ciberespacios a la vez virtuales y mentales.

e) Facebook y los lenguajes de la (inter)referencialidad, los vínculos, las emociones, las asociaciones entre texto, sonido, imágenes y la sensibilidad. Los imaginarios y los estilos comunicativos asociados a solidaridades, emociones e instituciones (familia, religión, amistad, pareja, vínculos primarios y secundarios, identificaciones afectivas, etc.). Nuevas modalidades de relación y receptividad en los vínculos virtuales. Facebook aumenta la exposición individual de las personas, pero esta exposición tal vez no promueve más comunicación o vínculos reales sino cierto voyerismo público. 
f) Facebook como producto y productor cultural. Viejos y nuevos mitos, creencias y valores. Asociaciones y actitudes manifiestas y latentes de reconocimiento o rechazo hacia instituciones "tradicionales" (casamiento, pareja, procreación, religión, educación, política, artes). Nuevos imaginarios y lenguajes, imágenes y representaciones culturales, verosimilitud. Modificaciones culturales que introduce Facebook como vehículo técnico y estético de expresión.

Pueden leerse las ideas anteriores como propuestas sobre la enumeración de líneas de interés o temas de investigación, pero sobre todo ofrecen una muestra de un modo particular de abordar múltiples dimensiones de análisis que presenta la adopción y el uso de un dispositivo técnico, un programa o un utilitario, y su incidencia "ecológica" sobre la complejidad de los procesos que atañen a las relaciones entre los sujetos y los dispositivos técnicos.

Abordamos el análisis de procesos sociales, institucionales y organizacionales desde la perspectiva de los actos y los dispositivos de comunicación (ya sean conversaciones, textos, lenguajes corporales, uso de objetos y dispositivos técnicos, relatos o mitos). Y abordamos a los sujetos (ya sea individual o colectivamente) como agentes sociales (actantes, según la terminología de Latour) que cultivan ecológicamente sus espacios ambientales (físicos y sociales, simbólicos y aun imaginarios). Es en este contexto ecológico que intentamos entender la irrupción de dispositivos técnicos como las TIC. Por último, no debemos olvidar que las TIC representan un papel día a día más fundamental para los procesos de emergencia y articulación social entre diferentes órdenes del mundo y de la vida. Funcionan precisamente como dispositivos convergentes de interfase. Internet ofrece acceso a recursos de información y comunicación, lo que genera un dominio de tiempos y espacios virtuales que transforma los medios $y$ las formas tradicionales de acceder a todos los dominios de la vida social. Los medios y las TIC se presentan como los intermediarios entre el mundo físico y los agentes sociales, haciéndolos converger por medio de la comunicación en una experiencia referencial "simbólica y cargada de sentido", a través de la cual una comunidad cultiva su ecología social y cultural. 


\section{Referencias}

Bajretarevic A. (2011). The cyber gulag revisited \& debate reloaded. Addleton Publishers, New York RCP, 10(2).

Barabási, A. L. (2003). Linked. How everything is connected to everything else and what it means to business, science and everyday life. Cambridge: Plume.

Clarín (2012, 11 de febrero). Una posición sobre privacidad. En Charaudeau, P. (1997), Le discours d'information médiatique. La construction du miroir social. París: Nathan.

Gorz, A. (2005). O imaterial: conhecimento, valor e capital. São Paulo: Annablume.

Jenkins, H. (s. f.). Convergence culture: Where old and new media collide. Nueva York: New York University.

Katz, J. (2006). Tecnologías de la información y la comunicación e industrias culturales. Una perspectiva Latinoamericana. Chile: Naciones Unidas-Cepal.

Keen, A. (2012). A nova forma de autoritarismo virtual. Revista Época, 4 de junio, 108-111.

Kerszberg, P. (2001). Phénoménologie de l'experience sonore. En Souza, T. \& Oliveira, N. F. (Orgs.), Fenomenología hoje. Existéncia, ser y sentido no alvorecer do século XXI. Porto Alegre: Edipucrs.

Latour, B. (2005). Reassembling the social. Introduction to actor-network theory. Oxford.

Lemoigne, J. L. (2005). La modélisation des systèmes complexes. París: Dunod. 
Lemos, A. (2015). Things (and People) are the tools of revolution! Ou como a Teoría Actor Rede resolve a purificação McLuhaniana do “meio como extensão do homem”. En Lo que McLuhan no predijo. Buenos Aires: La Crujía, Buenos Aires (en prensa).

Lévy, P. (2007). Cibercultura. La cultura de la sociedad digital. México, D. F.: Anthropos, Universidad Autónoma Metropolitana.

McLuhan, M. (1964). Understanding media. The extensions of man. NuevaYork: McGraw Hill.

Manovich, L. (2006). El lenguaje de los nuevos medios de comunicación. La imagen en la era digital. Buenos Aires: Paidós Comunicación.

Mosco V. (2005). La economía política de la comunicación: una actualización de diez años. Anuario Ininco, 17(2).

Moutier-Boutang, Y. (2007). A bioproduçao. O capitalismo cognitivo produz conhecimentos por meio de conhecimento e vida por meio de vida. Revista Humanitas, 216.

Negri, A. \& Lazaratto, M. (2001). Trabalho imaterial, formas de vida e produçao de subjetividade. Río de Janeiro: DP\&A.

Neves, R. (2007). O celular é a vara de pescar. Revista Época.

Postman, N. (1994). Tecnopólio. A rendição da cultura a tecnologia. São Paulo: Nobel.

Sohn-Rethel, A. (1976). Intellectual and manual labour. A critique of epistemology. Londres: Macmillan.

Vizer, E. A. (1992). Globalization and cooperation. Social actors on a new technologies and communication perspective. Anales del Congreso Calacs (Canadian Association for Latin and Caribbean Studies, Canadian Journal). 
Vizer, E. A. (1994). The challenges of developing a technological culture. Conferencia pronunciada en el Departamento de Información Pública de las Naciones Unidas, Nueva York. 1987 (Traducción: Telos, 37).

Vizer, E. A. (2005). Socioanálisis. Metodología de investigación, análisis diagnóstico e intervención social. Redes.com, 2. Instituto Europeo de Comunicación y Desarrollo. Recuperado el 14 de noviembre de 2014 de: alojamientos.us.es/cico/redes/index.htm

Vizer, E. A. (2006). La trama (in)visible de la vida social: comunicación, sentido y realidad. Buenos Aires: La Crujía.

Vizer, E. A. (2007). Procesos sociotécnicos y mediatización en la cultura tecnológica en la sociedad mediatizada. En Sociedad Mediatizada (p. 30). Barcelona: Gedisa.

Vizer, E. A. (2009). Social dimensions of communication; communicational dimensions of social processes. Some propositions on research lines and problematics. Famecos, 40., 9.

Vizer, E. A. (2010). Una perspectiva socioanalítica en la aplicación de tecnologías. Revista de Investigación Científica Gestión de las Personas y Tecnología. Recuperado el 14 de noviembre de 2015 de: www. tap.usach.cl/gpt

Vizer, E. A. (2011). A trama (in)visível da vida social: comunicação, sentido e realidade. Porto Alegre: Sulina.

Vizer, E. \& Carvalho, H. (2012a). A caixa de Pandora. Tendências e paradoxos das TICs. En Barichello, E. \& Machado, A. (orgs.), Estratégias Mediáticas. Santa Maria: Facos-UFSM.

Vizer, E. \& Carvalho, H. (2012b). La caja de Pandora. En Vizer, E. \& Carvalho, H., Comunicación y socioanálisis. Estrategias de investigación e intervención social. Alemania: EAE/Amazon 
Vizer, E. \& Carvalho, H. (2012c). El ojo de Dios: conectados y vigilados. En Benevenuto, Á. Jr. \& Steffen, C., Tecnologia praquê? Os impactos da tecnologia no campo da comunicação. Porto Alegre: Armazém Digital.

Wellman, B. (2004). The three ages of Internet studies: Ten, five and zero years ago. EE. UU.: New Media and Society. 